\title{
SISTEM INFORMASI PEMBELIAN BARANG MENGGUNAKAN METODE VALUE CHAIN
}

\author{
Ageng Setiani Rafika ${ }^{1}$ \\ Tamara Dian Anggiani ${ }^{2}$ \\ Ananda Dian Alifah ${ }^{3}$ \\ Dosen STMIK Raharja ${ }^{1}$, STMIK Raharja Jurusan Sistem Informasi ${ }^{2,3}$ \\ Jl. Jendral Sudirman No. 40 Modern Cikokol - Tangerang \\ Email:agengsetianirafika@raharja.info,anggi.dian@raharja.info,ananda.dian@raharja.info
}

\begin{abstract}
ABSTRAK
Proses pembelian merupakan salah satu kegiatan utama pada sebuah perusahaan dimana proses tersebut berperan penting pada tingkat penjualan perusahaan dimana pada proses pembelian tersebut perusahaan dapat menentukan harga jual pada sebuah produk. Dalam kegiatannya proses pembelian tidak cukup hanya dengan sistem manualkarena adanya pemisahan fungsi dimana resiko kesalahan atas pembelian lebih besar sehingga di perlukan sistem yang lebih baik lagi. Kegiatan yang dimulai dari permintaan pengadaan barang, pembelian barang, pengiriman barang, pengolahan laporan pembelian ke pimpinan merupakan tahapan dalam proses pembelian.Perancangan sistem informasi pembelian pada penelitian ini adalah menggunakan metode analisis Value Chain, dimana metode tersebut dapat memberikan informasi yang terperinci untuk mendapatkan keunggulan pada sebuah sistem. Hasil yang di dapat dalam metode Value Chain adalah sebuah sistem pembelian berbasis web menggunakan database MySQL yang dapat di akses secara online untuk kegiatan pembelian dan terintegrasi pada fungsi terkait. Dengan sistem online ini maka segala aktifitas pembelian akan berlangsung secara update baik aktifitas ataupun data yang tersedia sehingga meminimalisasikan kesalahan humaneror atau kesalahan data.
\end{abstract}

Kata Kunci: Sistem Pembelian, Value Chain, MySQL, Humaneror

\begin{abstract}
Purchase process is one of the main activities in a company where process important role at the level of sales of companies where the purchase process companies can determine the selling price on a product. In the course of the purchase process is not enough just with the manual system because of the separation of functions where the risk of error on the purchase is greater so that in need of a better system again. Activities that start from the demand for goods procurement, goods purchases, delivery of goods, processing of purchasing reports to the leadership is the stage in the purchase process. The design of purchasing information system in this research is to use Value Chain analysis method, where the method can provide detailed information to gain excellence in a system. The results method value chain is a web-based purchasing system using a MySQL database that can be accessed online for purchasing activities and integrated in related functions. With this online system then all purchasing activities will take place in an update either activity or data available so as to minimize humaneror or data errors.
\end{abstract}

Keywords: Purchasing System, Value Chain, MySQL, Humaneror 


\section{PENDAHULUAN}

Dalam sebuah perusahaan proses kegiatan tidak lepas dari adanya transaksi pembelian barang sebagai pemenuhan kegiatan perusahaan dalam rangka menghasilkan sebuah produk sehingga kegiatan pembelian menjadi salah satu kegiatan utama bagi sebuah perusahaan.

PT. Teknotama Lingkungan Internusa merupakan salah satu perusahaan yang bergerak dibidang pengelolahan limbah B3 (bahan, beracaun dan berbahaya).

Sistem Pembelian yang berjalan saat ini melalui prosedur yang cukup kompleks mengingat perusahaan memiliki banyak fungsi, yang tentunya fungsi-fungsi ini saling bekerjasama dalam melakukan pembelian dan mempunyai tanggung jawab yang berbedabeda tetapi tetap saling bekerjasama untuk kelancaran transaksi pembelian.

Dengan kompleksnya prosedur pembelian yang berjalan saat ini, namun belum di dukung oleh sistem yang memadai karna pada kegiatan pembelianmasih menggunakan Software Microsoft Excel, dimana Software tersebut digunakan untuk membuat PO (Purchase Order), pencatatan barang masuk dari pemasok hingga membuat laporan pembelian ke pimpinan.

Sistem pembelian yang berjalan saat ini kurang optimal sehingga menyebabkan banyaknya human eror dalam kegiatan pembelian sehingga menimbulkan data yang tersedia tidakvalid.

\section{PERMASALAHAN}

Berdasarkan uraian diatas di dapat permasalahan yang terjadi yaitu kurangoptimalnya kegiatan pembelian pada sistem pembelian yang saat ini berjalan dan tidak data yang tidak valid pada PT. Teknotama Lingkungan Internusa dikarenakan sistem yang di pakai masih semi terkomputerisasi.

\section{TINJAUAN PUSTAKA}

\section{A. Definisi Sistem}

Menurut Hutahaean (2015:2) ${ }^{[1]}$, "Sistem adalah suatu jaringan kerja dari prosedurprosedur yang saling berhubungan, berkumpul bersama-sama untuk melakukan kegiatan atau untuk melakukan sasaran yang tertentu. “"

\section{B. Definisi Informasi}

Menurut Hutahaean $(2015: 2)^{[1]}$, "Informasi adalah data yang diolah menjadi bentuk yang lebih berguna dan lebih berarti bagi penerimanya."

\section{Definisi Pembelian}

Menurut Kriswanto (2014:358) $)^{[2]}$, "Pembelian merupakan suatu struktur interaksi antara orang-orang, peralatan, metode-metode, dan pengendalian yang dirancang untuk mencapai fungsi fungsi utama sebagai berikut: (1) Menangani rutinitas pekerjaan yang berulang-ulang dari bagian pembelian dan penerimaan. (2) Mendukung pengambilan keputusan dari orangorang yang mengatur bagian pembelian dan penerimaan. (3) Membantu dalam penyajian laporan internal dan laporan eksternal. 


\section{Definisi Value Chain}

Menurut Porter dalam Sulaksono (2014:95) ${ }^{[3]}$, “Analisis Value Chain merupakan alat analisis strategi yang digunakan untuk memahami secara lebih baik terhadap keunggulan kompetitif".

\section{E. Kerangka Rantai Nilai Value Chain}

Menurut Hitt dalam Wisdaningrum (2013:42) ${ }^{[4]}$, kerangka rantai nilai membagi aktivitas dalam perusahaan menjadi dua kategori umum:

1. Aktifitas primer (primary activities) Aktivitas yang berkaitan dengan penciptaan fisik produk, penjualannya dan distribusinya ke para pembeli, dan servis setelah adanya penjualan.

2. Aktifitas pendukung (support activities) Membantu perusahaan secara keseluruhan dengan menyediakan dukungan yang diperlukan bagi berlangsungnya aktivitas-aktivitas primer dilakukan secara berkelanjutan. Menurut Pears and Robinson dalam Wisdaningrum (2013:42), berikut gambar yang menjelaskan mengenai aktivitas-aktivitas yang dilakukan, yaitu:

F. Definisi UML

Menurut Fowler dalam Syukron (2015:30) ${ }^{[5]}$, "Unifield Modelling Language (UML) adalah keluarga notasi grafis yang didukung oleh meta model yang membantu pendeskripsian dan desain sistem perangkat lunak, khususnya sistem yang dibangun dengan menggunakan pemrograman berorientasi objek (oop)"

\section{METODE PENELITIAN}

Peneliti menggunakan teknikdeskriptif dalam pengumpulan data dengan melakukan observasi, wawancara langsung pada Departemen Purchasingserta studi pustaka.

Dalam penelitian ini,peneliti menggunakan metode analisa Value Chain dan bagan alir program (Flowchart Program). Perancangan sistem menggunakan UML (Unifed Modeling Language) dengan software visual Paradigm for UML 8.0 Interprise Editionyaitu Use Case Diagram, Activity Diagram, Squance Diagram untuk menggambarkan sistem pembelian yang berjalan dan diusulkan.

\section{PEMBAHASAN}

Sistem pembelian yang berjalan saat inimasih menggunakan sistem semi komputerisasi yaitu menggunakan Software Microsoft Excel sehingga pada kegiatan pembelian masih banyaknya terjadihuman eror.

Prosedur permintaan barang yang berjalan saat ini dimulai dengan Staff Gudang membuat form permintaan barangdan mengisi detail barang, jumlah dan waktu yang dibutuhkan untuk selanjutnya di ajukan approval ke Manager Gudang. Setelah di Approval permintaan barang di proses oleh bagian admin purchasing dan Staff Purchasing untuk proses pembelian barang yang dibutuhkan. Dalam tahap ini Staff Purchasing melakukan pencarian supplier dan melakukan negosiasi harga untuk mendapatkan harga yang terbaik.

Pembelian barang yang telah dilakukan diajukan ke pimpinan untuk di approval dan setelah di approval maka proses pembelian barang dapat di lakukan.

Perbedaan sistem yang berjalan dengan sistem yang diusulkan sebagai berikut: 
Table 1. Perbedaan Sistem Berjalan Dengan Sistem Usulan

\begin{tabular}{|c|c|c|}
\hline No & Sistem yang berjalan & Sistem yang diusulkan \\
\hline 1 & $\begin{array}{l}\text { User membuat form permintaan barang manual } \\
\text { dengan menggunakan tulisan tangan sebelum } \\
\text { di ajukan ke pimpinan }\end{array}$ & $\begin{array}{l}\text { User membuat form permintaan barang secara } \\
\text { online sebelum di ajukan ke pimpinan }\end{array}$ \\
\hline 2 & $\begin{array}{l}\text { Kegiatan pembelian dari awal proses pembelian } \\
\text { hingga pembuatan laporan pembelian } \\
\text { menggunakan Ms Excel kemudian di print dan } \\
\text { di ajukan ke pimpinan. }\end{array}$ & $\begin{array}{l}\text { Kegiatan pembelian dari awal proses pembelian } \\
\text { hingga pembuatan laporan pembelian } \\
\text { dilakukan secara online dan terintegrasi dengan } \\
\text { Departement Gudang untuk selanjutnya di } \\
\text { laporkan ke pimpinan }\end{array}$ \\
\hline 3 & $\begin{array}{l}\text { Saat proses pengadaan barang masih manual, } \\
\text { pembelian barang dilakukan sesuai dengan item } \\
\text { dan jumlah yang tercantum pada PR tanpa adanya } \\
\text { pengecekan terlebih dahulu stok barang yang tersedia }\end{array}$ & $\begin{array}{l}\text { Proses pengadaan barang secara online dan } \\
\text { terintegrasi dengan Departemen Gudang sehingga } \\
\text { sebelum pengadaan barang di cek terlebih dahulu } \\
\text { stok yang ada untuk menghindari kelebihan barang } \\
\text { di gudang }\end{array}$ \\
\hline
\end{tabular}

Berdasarkan perbedaan sistem yang berjalan dengan sistem usulan, berikut penjelasan dalam bentuk diagram untuk sistem pembelian yang berjalan saat ini sebagai berikut:

\section{A. Use Case Sistem Yang Berjalan}

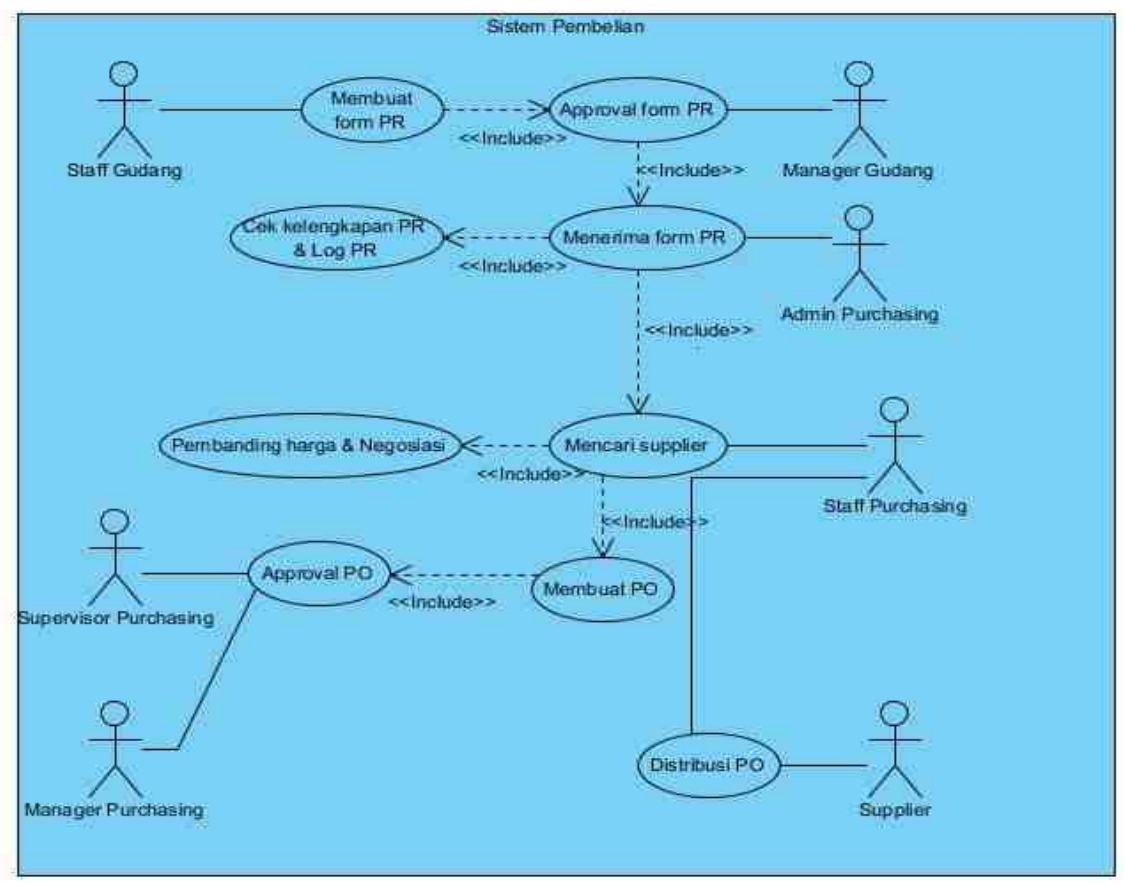

Gambar 1. Usecase Diagram

Dapat di jelaskan pada gambar usecase diatas terdapat 7 actor dan 9 usecase yang dilakukan oleh actor, dimulai dari:

1 Staff Gudang membuat form permintaan barang dengan mengisi detail barang, jumlah barang dan waktu yang dibutuhkan untuk pemenuhan barang.

2 Manager Gudang melakukan approval atas permintaan barang yang di ajukan Staff Gudang sebelum diberikan ke Admin purchasing

3 Permintaan barang yg sudah di approval di berikan ke Admin Purchasing

4 Setelah permintaan barang di terima, selanjutnya dilakukan pengecekan detailbarang serta kartu stok jika sudah lengkap maka permintaan barang di log serta diberikan ke Staff Purchasing dan jika tidak lengkap maka permintaan barang dikembalikan kembali ke 


\section{Staff Gudang}

5 Permintaan barang yang telah diterima selanjutnya dicarikan supplier, minimal 2 supplier yang dapat memasok kebutuan sesuai dengan detail barang yang dibutuhkan.

6. Setelah dilakukan pencarian supplier staff purchasing melakukan pembandingan harga dari 2 supplier yang telah di dapat dan dilakukan negosiasi harga untuk mendapatkan harga yang terbaik.

7. Setelah dilakukan pembanding harga dan negosiasi harga,Staff Purchasing membuat PO sesuai dengan permintaan barang yang di ajukan.

8. Setelah PO di buat selanjutnya PO di ajukan ke pimpinan untuk proses approval sebelum dilakukannya pemesanan barang

9. PO yang sudah di approval selanjutnya di distribusikan ke supplier untuk selanjutnya di proses pengiriman barang.

\section{B. Activity Diagram}

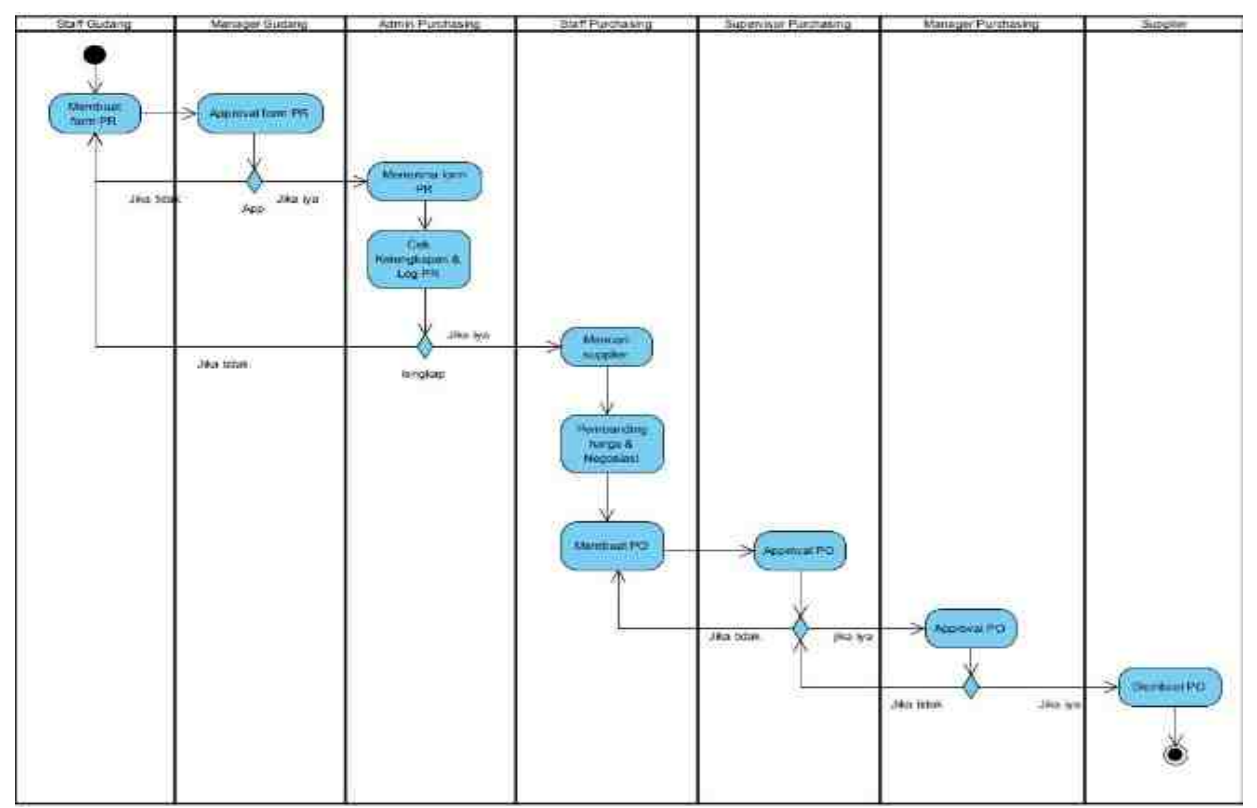

Gambar 2. Activity Diagram

Pada gambar activity diagram di atas terdiri dari 1 Initial Node, 10 Action, 4 Decision Node dan 1 Activity Final Node dengan detail sebagai berikut:

1. 1 (satu) Initial Node

2. 10 (sepuluh) Action, meliputi:

1. Membuat form PR

2. Approval form PR

3. Menerima form PR

4. Cek kelengkapan \& $\log P R$

5. Pencarian supplier

6. Perbandingan harga \& Negosiasi

7. Membuat PO

8. Approval PO oleh Supervisor

Purchasing

9. Approval PO oleh Manager

Purchasing 


\section{Distribusi PO}

3. 4 (empat) Decision Node

4. 1 (satu) Activity Final Node

\section{Sequance Diagram}

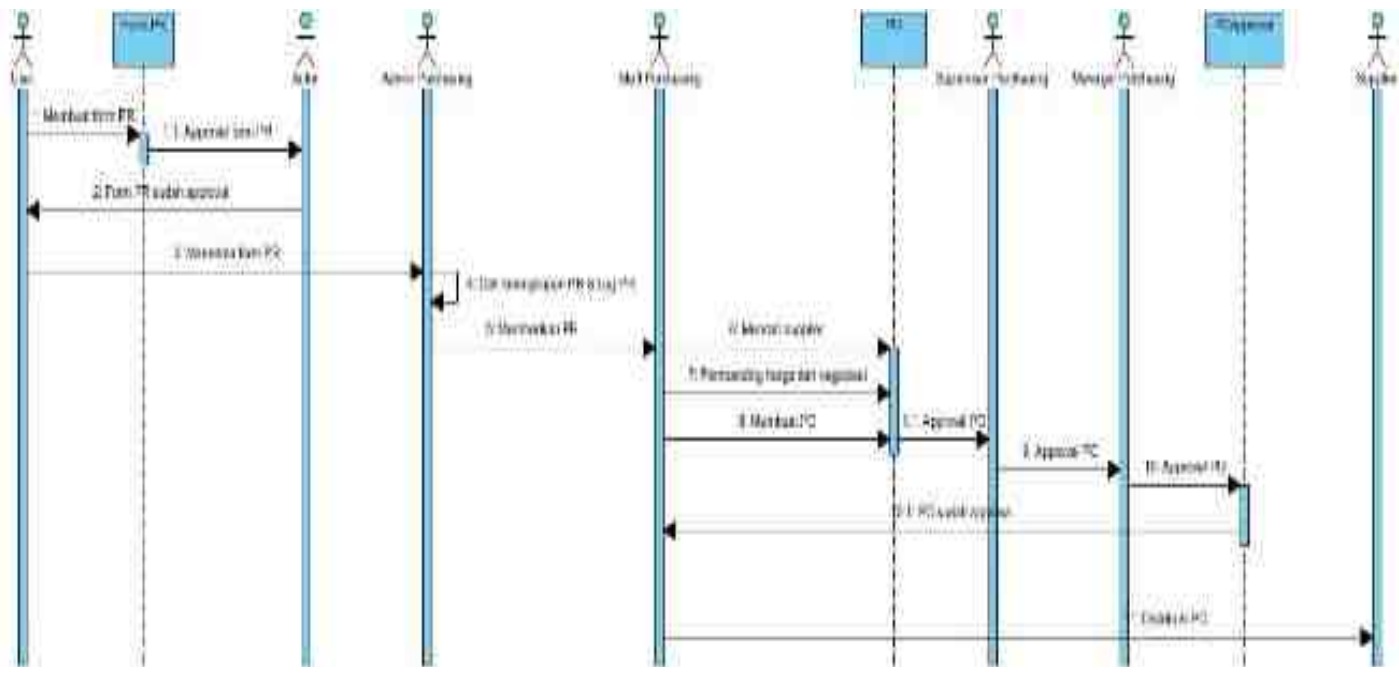

Gambar 3. Sequance Diagram

Dapat di jelaskan pada gambar sequence diagram di atas terdiri dari 3 lifeline, 7 actor dan 11 message, bahwa staff gudang membuat form PR lalu di ajukan approval ke Manager Gudang, setelah di approval maka PR di di berikan ke Admin Purchasing untuk selanjutnya di cek kelengkapan dan log PR sebelum di berikan ke Staff Purchasing. Setelah dilakukannya log maka form PR akan diberikan ke Staff Purchasing untuk selanjutnya di carikan supplier, pembanding harga dan negosiasi serta di buatkan PO. PO yang sudah di buat akan di berikan ke Supervisor dan Manager Purchasing untuk dilakukannya approval PO, dan PO yang sudah di approval akan di berikan kembali ke Staff Purchasing untuk di distribusikan ke Supplier agar proses pemesanan barang dapat dilakukan.

\section{Value Chain}

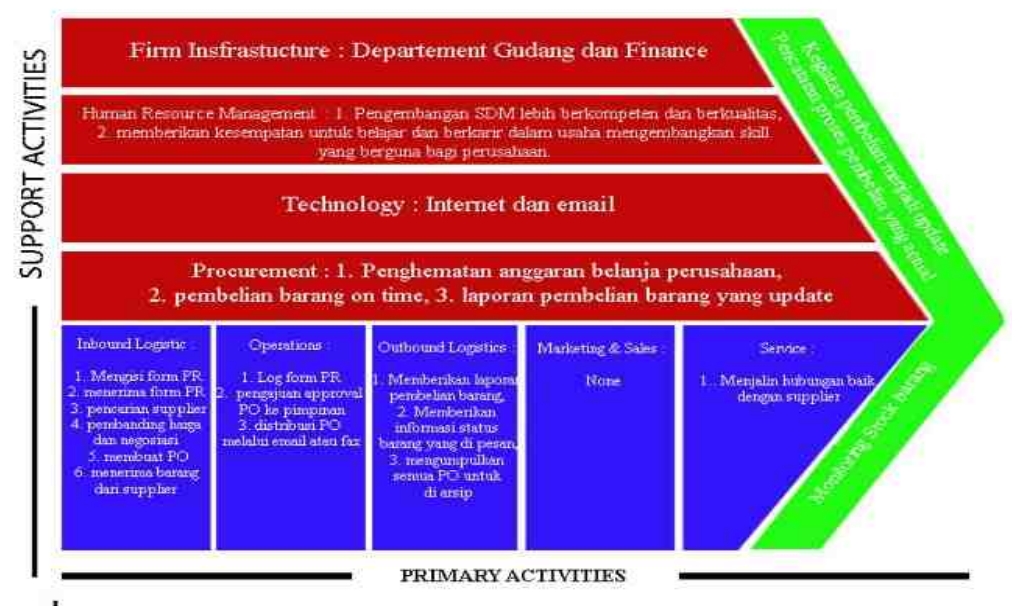

Gambar 4. Value Chain 
Aktivitas utama (primary activities) yang terdapat pada analisa Value Chain pada sistem pembelian pada PT. Teknotama Lingkungan Internusa, adalah sebagai berikut:

1. Inbound Logistic : Mengisi form PR, menerima form PR, pencarian supplier, pembanding harga dan negosiasi, membuat $\mathrm{PO}$, menerima barang dari supplier

2. Operations : Log form PR, pengajuan Approval PO ke pimpinan, distribusi PO melalui email atau fax

3. Outbound Logistics : Memberikan laporan pembelian barang, memberikan informasi status barang yang di pesan, mengumpulkan semua PO untuk di arsip

4. Marketing \& Sales :None

5. Service : Menjalin hubungan baik dengan supplier

Adapun aktivitas pendukung (support activities) yang terdapat pada analisa Value Chain pada sistem pembelian pada PT. Teknotama Lingkungan Internusa, adalah sebagai berikut:

1. Firm Insfrastucture : Departement gudang dan finance

2. Human Resource Management:Pengembangan SDM lebih berkompeten dan berkualitas, memberikan kesempatan untuk belajar dan berkarir dalam usaha mengembangkan skill yang berguna bagi perusahaan.

3. Technology : Internet dan email

4. Procurement :Penghematan anggaran belanja perusahaan, pembelian barang on time, laporan pembelian barang yang update

Dan yang menjadi margin pada sistem sistem pembelian pada PT. Teknotama Lingkungan Internusa, adalah sebagai berikut:

1. Kegiatan pembelian menjadi update

2. Pencatatan proses pembelian yang actual

3. Monitoring Stok barang

\section{E. Permasalahan Yang Dihadapi}

Berdasarkan sistem yang sedang berjalan, dalam operasional pembelian barang masih sering terjadinya human eror seperti kesalahan dalam pecatatan data pembelian, perhitungan nominal jumlah pembelian sehingga menyebabkan data yang tidak valid.

\section{F. Alternatif Pemecahan Masalah}

Membuat sistem operasional pembelian berbasis web agar meminimalisasikan human eror dan memberikan kemudahan dalam kegiatan operasional pembelian sehingga dapat bekerja dengan cepat, tepat dan akurat. 


\section{RANCANGAN SISTEM}

1. Rancangan Database

Class Diagram

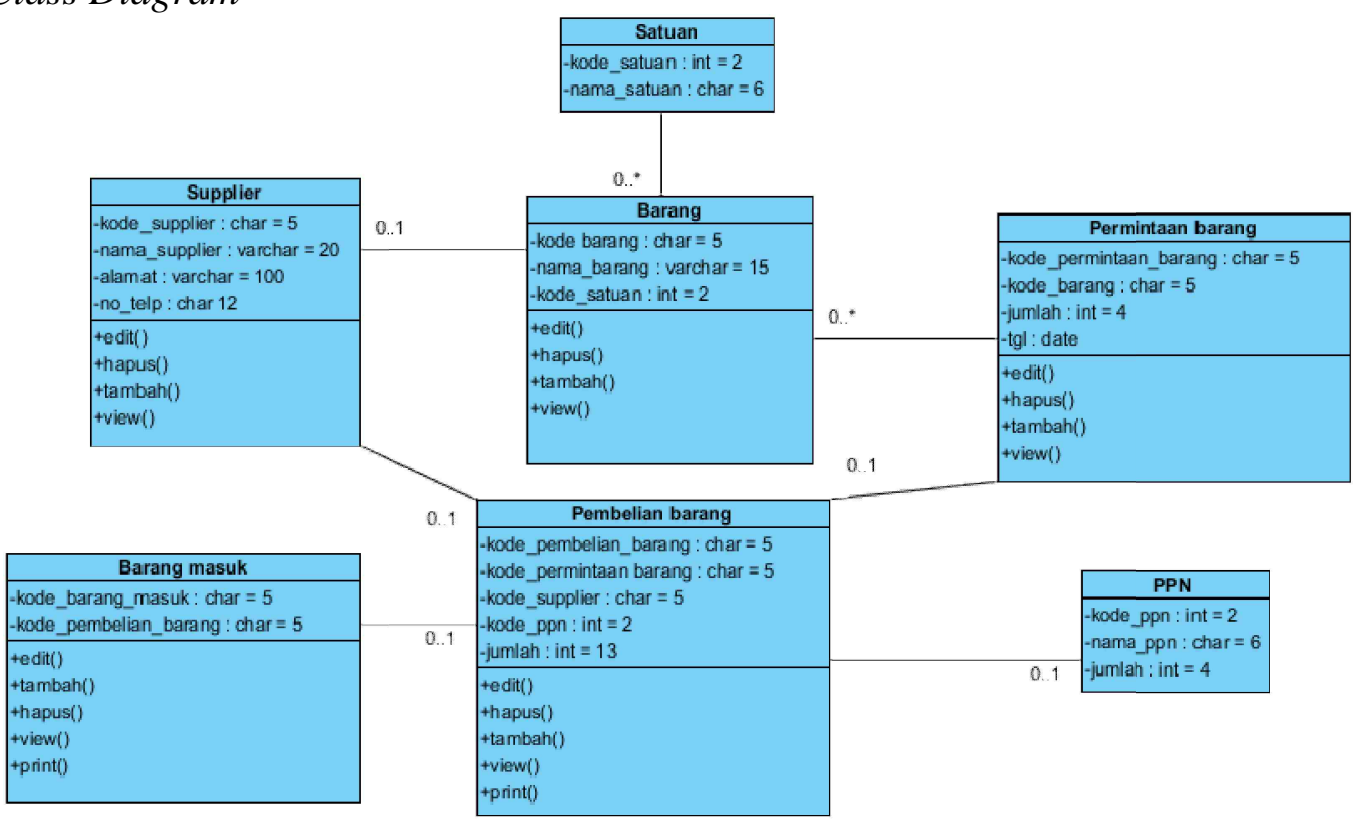

Gambar 5. Class Diagram

Dapat di jelaskan pada gambar class diagram di atas terdiri dari 7 class sebagai berikut:

- Supplier

- Barang

- Satuan

- PPN

- Permintaan Barang

- Pembelian Barang

- Barang Masuk

\section{Perancangan Prototype}

a. Rancangan Login

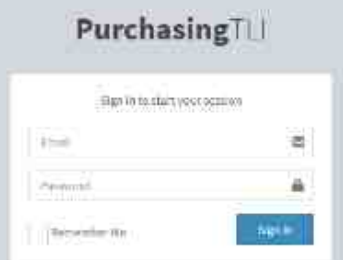

Gambar 6. Rancangan Login 
Sebuah sistem dibutuhkan tingkat keamanan yang tinggi untuk menjaga data yang terdapat pada sebuah sistem. Sistem pembelian yang dirancang juga dilengkapi dengan sistem login dengan memasukan alamat email dan kata sandi untuk masuk kedalam sistem pembelian.

\section{b. Rancangan Permintaan Barang}

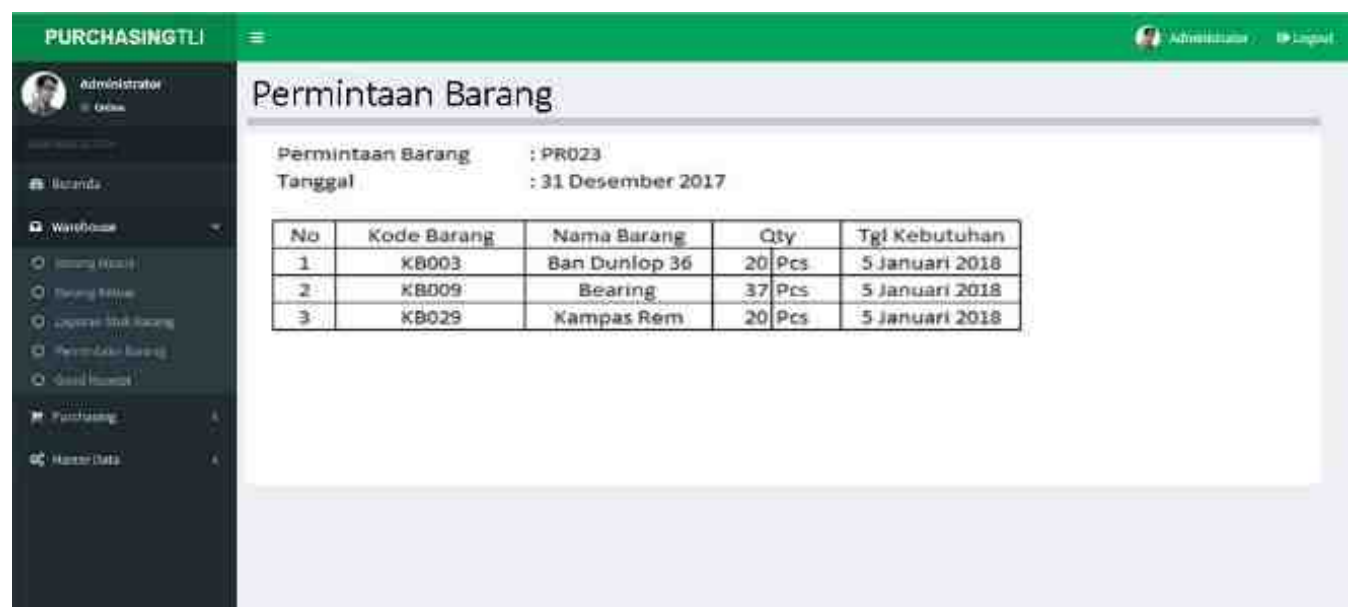

Gambar 7. Rancangan Permintaan Barang

Proses pembelian barang di awali dengan permintaan barang, Departemen Gudang membuat permintaan barang dengan memasukan data item barang yang dibutuhkan serta jumlah masing masing barang dan juga tanggal yang dibutuhkan untuk pengadaan barang tersebut.

\section{c. Rancangan Pembelian Barang}

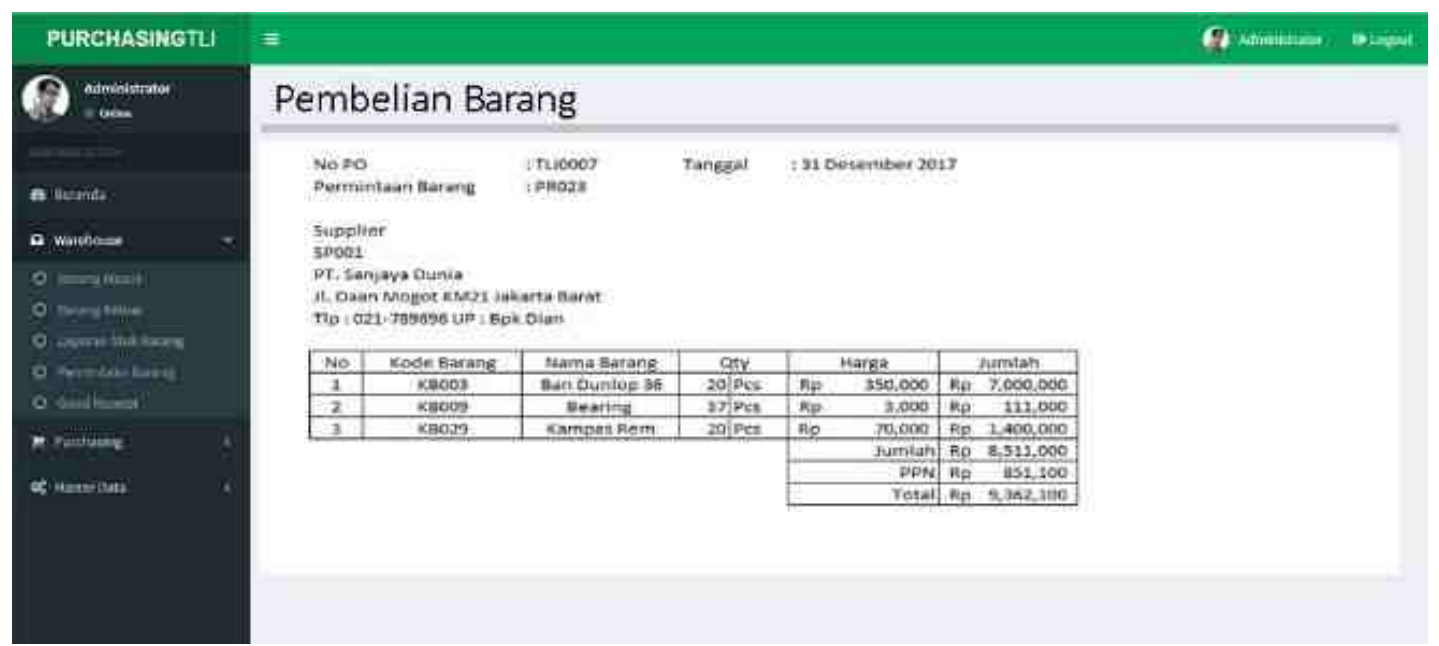

Gambar 8. Rancangan Pembelian Barang

Dalam pembelian barang, sistem secara otomatis terintegrasi dengan permintaan barang yang telah dibuat Departement Gudang dengan menarik data nomor permintaan barang yang 
telah dibuat dan dilanjutkan dengan memasukan harga satuan pada masing - masing barang dan di jumlahkan secara otomatis oleh sistem.

\section{d. Rancangan Barang Masuk}

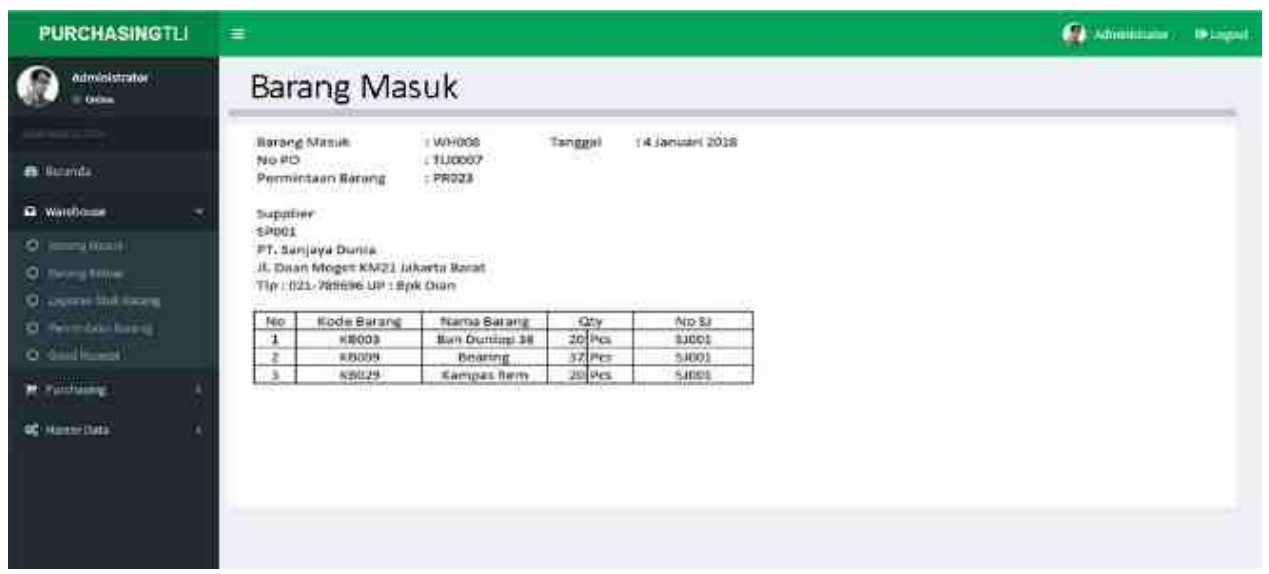

Gambar 9. Rancangan Barang Masuk

Barang yang dikirim oleh supplier berdasarkan surat pembelian barang akan masuk dalam gudang dan di input kedalam sistem dengan menarik data nomor pembelian barang dan menambahkan informasi surat jalan supplier untuk kebutuhan pendataan barang yang telah masuk ke dalam gudang.

\section{e. Rancangan Laporan Pembelian}

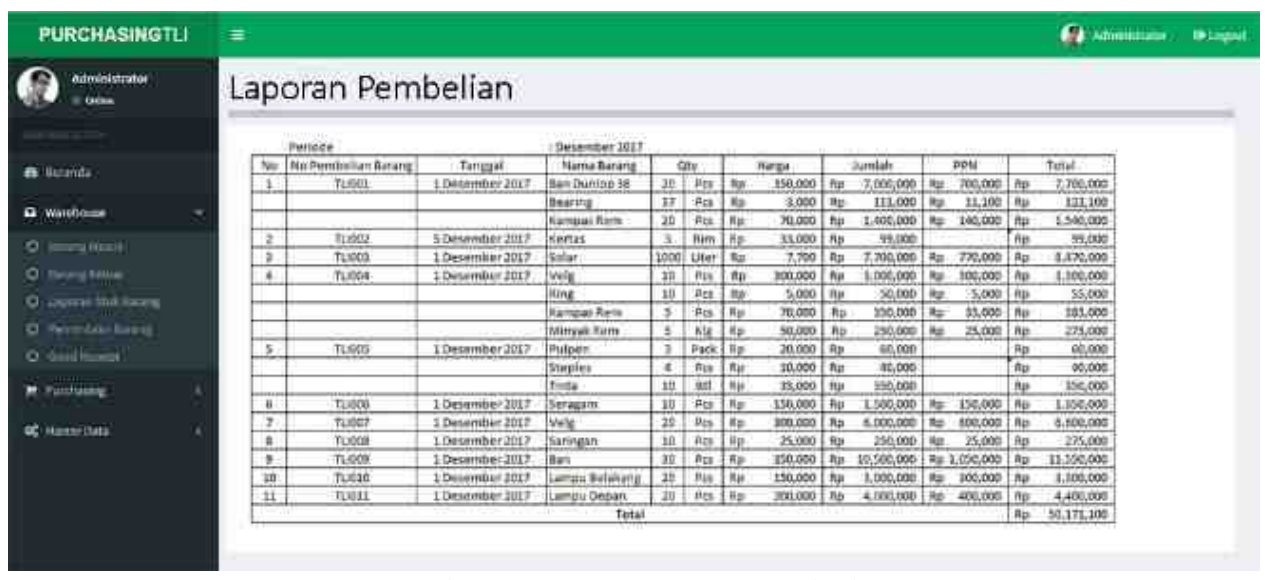

Gambar 10. Laporan Pembelian

Sistem dapat membuat laporan pembelian dalam periode selama 1 bulan dengan memasukan bulan yang akan di buatkan laporan atau dibutuhkan informasi laporan pembelian pada bulan tertentu. Pada laporan pembelian akan di muat informasi detail pembelian barang, item barang dan jumlah barang yang di pesan serta jumlah biaya yang telah dikeluarkan perusahaan untuk proses pembelian dalam 1 bulan 


\section{KESIMPULAN}

Berdasakan hasil penelitian yang telah dilakukan maka dapat di ambil kesimpulan sebegai berikut:

1. Perusahaan sudah menggunakan sistem yang semi terkomputerisasi, yaitu dengan software Microsoft Excel untuk setiap kegiatan pembelian sehingga menyebabkan kurang optimalnya pada kegiatan pembelian perusahaan.

2. Sistem yang berjalan saat ini sering terjadinya human eror seperti kesalahan dalam pecatatan data pembelian, perhitungan nominal jumlah pembelian sehingga menyebabkan data yang tidak valid.

\section{DAFTAR PUSTAKA}

[1]Hutahaean, Jeperson 2015. Konsep Sistem Informasi. Yogyakarta: Deepublish

[2]Kriswanto, 2014. Analisa \& Evaluasi Sistem Pembelian Persediaan \& Penjualan TunaiPada PT. ZRB. Binus Business Review Vol. 5 No. 1

[3]Sulaksono, Juli, Abidarin Rosidi, Syamsul A Syahdan. 2014. Perencanaan Strategis Sistem Informasi di Universitas Nusantara PGRI Kediri. Kediri: STMIK AMIKOM Yogyakarta

[4]Wisdaningrum, Oktavima. 2013. Analisis Rantai Nilai (Value Chain) dalam lingkungan internal perusahaan. Banyuwangi: Universitas 17 Agustus 1945

[5]Syukron, Akhmad dan Noor Hasan. 2015. Perancangan Sistem Informasi Rawat Jalan Berbasis Web Pada Puskesmas Winong. Jurnal Bianglala Informatika. Vol.3, No.1 